MIDAS

Museus e estudos interdisciplinares

2 | 2013

Varia

\title{
José Maria Amado Mendes - Museus e Educação.
} Estudos, Humanidades

Irene Vaquinhas

\section{OpenEdition}

Journals

Édition électronique

URL : http://journals.openedition.org/midas/299

DOI : 10.4000/midas.299

ISSN : 2182-9543

Éditeur :

Alice Semedo, Paulo Simões Rodrigues, Pedro Casaleiro, Raquel Henriques da Silva, Ana Carvalho

Référence électronique

Irene Vaquinhas, "José Maria Amado Mendes - Museus e Educação. Estudos, Humanidades », MIDAS [En ligne], 2 | 2013, mis en ligne le 03 avril 2013, consulté le 22 septembre 2020. URL : http:// journals.openedition.org/midas/299; DOI : https://doi.org/10.4000/midas.299

Ce document a été généré automatiquement le 22 septembre 2020

\section{(c) (i) (2)(2)}

Midas is licensed under a Creative Commons Attribution-NonCommercial-ShareAlike 3.0 International License 


\title{
José Maria Amado Mendes - Museus e Educação. Estudos, Humanidades
}

\author{
Irene Vaquinhas
}

\section{RÉFÉRENCE}

Mendes, José Maria Amado. 2009. Museus e Educação. Estudos, Humanidades. Colecção Estudos do Património. Coimbra: Imprensa da Universidade. 231 páginas, ISBN:

978-989-8074-81-2.

1 O livro Estudos do Património. Museus e Educação reproduz comunicações feitas no âmbito de congressos e de colóquios, tanto nacionais como internacionais, bem como artigos publicados em revistas académicas, de diversas universidades, públicas e privadas. Não obedece a um critério cronológico, embora todos os textos se situem num arco temporal que vai desde 1990 (o mais antigo) a 2006 (o mais recente), incidindo, sobretudo, na primeira década do século XXI.

2 Essa convergência cronológica confere, desde logo, à obra um grande vigor, permitindo qualificá-la com um expoente significativo de preocupações recentes nos campos da museologia e do património cultural e, muito em particular, das mais hodiernas manifestações do pensamento, tanto europeu como americano, nessas áreas do saber, e que o autor revela conhecer em profundidade. A atualização científica, tanto em termos de estudos teóricos e metodológicos, como práticos e empiristas, atravessa todo o volume, como um elemento recorrente, lançando propostas estimulantes quer em direção à natureza caleidoscópica e plural da noção de património, quer para os aspectos mais inovadores da museologia, entendida como suporte dinâmico da comunicação com os cidadãos, os principais destinatários de qualquer política cultural.

3 A coerência interna do livro (implícita mas não explícita) é dada pela articulação e pela interdependência de três dimensões essenciais: a patrimonial, a museológica e a educativa, mesmo quando estas se apresentam autónomas. 0 aprofundamento epistemológico dos conceitos de património e de museu constitui o enquadramento 
geral do volume, a urdidura dos seus estudos, dando guarida aos vários textos que se abrem em reflexões problematizadoras, tendo por base os vários assuntos historiográficos objecto de investigação ou estudos de caso.

Determinadas ideias-chave, ou linhas tendenciais, conforme a perspetiva, estruturam o volume, que o autor vai retomando ao longo dos textos, como se tratassem do seu fio de Ariadne, e que procurarei sintetizar de uma forma breve:

5 1. A primeira consiste no alargamento do conceito de património cultural nas últimas décadas, incorporando novas realidades, e o importante papel que este desempenha nas atuais políticas culturais, tanto em termos pedagógicos, ao reforçar identidades, como pelo valor económico, como fonte de riqueza. Neste âmbito, é destacado o papel da arqueologia industrial, área de estudos da qual o autor é um consagrado especialista. Se, nos finais do século XIX, o património poderia ser definido como a "vitrine do génio nacional", no momento em que a palavra cristalizara na noção de monumento histórico, herdada da Revolução Francesa, a partir dos anos sessenta do século XX, o conceito não tem cessado de se expandir, incorporando os testemunhos de um tempo desaparecido, e orientando-se em direção a realidades que, sem poderem ser qualificadas como de excepcional valor, são representativas de uma identidade: nacional, regional ou local. Esta metamorfose corresponde a uma evolução silenciosa mas decisiva: a passagem da história nacional à memória nacional, na expressão feliz do historiador François Furet. Por outras palavras: à passagem de uma consciência histórica da nação a uma consciência social, decorrente de uma profunda e progressiva democratização, a qual converteria o património naquilo que alguns autores qualificam de "o sagrado laico das sociedades contemporâneas”. Desta forma, ao lado da peça única, de excepcional valor, pode conviver o singelo objecto quotidiano, entendido como um sinal ou um pretexto para se aceder à compreensão dos processos da sua produção, do seu fabrico ou uso, mantendo presente na memória os acontecimentos que testemunhou. "Terminou a ditadura do documento escrito - escreve Amado Mendes, parafraseando Jacques Le Goff - adiantando que "os objetos relacionados com os homens comuns, quantas vezes anónimos, passaram a ser considerados como documentos, isto é, fontes para o estudo da humanidade, podendo ser musealizados" (p. 62).

6 É dentro deste contexto do alargamento do conceito de património - que não é, contudo, consensual como o próprio adverte - que se inscrevem alguns dos estudos deste volume. Analisa a esse propósito alguns casos pontuais, evocando tanto o infinitamente grande como o infinitamente pequeno, ou melhor, tanto os "monumentos industriais", seja no estrangeiro, seja em solo nacional, como singulares objetos quotidianos. A este propósito, detém-se em pormenor sobre a Central térmica dos Hospitais da Universidade de Coimbra, vulgo edifício das caldeiras (p. 215-231), sobre os fornos da cal do concelho de Cantanhede (p. 83-91), sobre as indústrias papeleiras do distrito de Coimbra (p. 133-142), ou, ainda, sobre a arte do ferro forjado (p. 143-154). Partindo do pressuposto de que "o património industrial é um novo território a explorar (art. Museologia e Património Industrial, p. 73-81) chama a atenção para as suas potencialidades em termos museológicos, exemplificando com casos nacionais e internacionais, realidades que revela conhecer muito bem, desde as longínquas paragens do Japão à vizinha Espanha.

7 Preservar, revalorizar, qualificar, as instalações industriais ou os saberes-fazer são a sua preocupação constante, a ideia-força que persegue nesses textos, considerando-os um recurso económico fundamental, capazes de gerir dinamismos e de assumir uma 
parte da sua sustentabilidade. A este propósito, afirma na p. 142, "O património histórico e cultural quando bem conservado, gerido e aproveitado, deixa de ser um peso morto, para passar a ser um factor de desenvolvimento, sob os vários pontos de vista, não só social e cultural, mas também económico. Poderá proporcionar a criação de emprego, a atração do público, a aquisição de bens, a utilização de serviços, a captação de recursos".

O alargamento do conceito de património cultural em estreita articulação com a influência doutrinária do movimento da nova museologia, verificada sobretudo a partir dos anos oitenta do século XX, teve um impacto decisivo no surgimento de novas experiências museológicas, como os museus de sociedade, museus de vizinhança ou os ecomuseus, temas que neste volume são largamente debatidos, dando ainda o mote a ideias e programas museológicos ainda não ensaiados que visam, acima de tudo, dar futuro ao passado, face a uma memória em risco acelerado de perda. Lança desafios no sentido da ideia-conceito de património europeu, a exemplo de património da humanidade (p. 107-117), ou, ao nível regional, o lançamento da rota do papel no triângulo Lousã-Góis-Serpins (p. 142). No momento em que se coloca a possibilidade de aplicação do conceito de low cost aos equipamentos culturais, o autor apela à necessidade de compatibilizar espaços públicos com criatividade, desenvolvimento económico e turismo cultural.

9 2. Duas outras ideias-chave estruturam o volume: por um lado, a de "explosão museológica", ou seja, o aumento exponencial do número de museus a partir dos anos oitenta do século XX, fenómeno que, em Portugal, apresenta números esclarecedores; por outro lado, a ideia da importância que a função educativa tem assumido no contexto geral das funções museológicas, fruto da própria evolução da instituição museu, transitando-se de uma política museística centrada nos objetos, sua aquisição e conservação para os sujeitos que deles beneficiam, ou seja, o público. A mudança de paradigma no conceito de museu (o autor fala mesmo de uma revolução coperniciana da museologia), a qual implica a passagem da museologia para a consciência social e política, mudança que ocorreu em simultâneo com a internacionalização da cultura, teve múltiplas implicações em vários sectores, desde a cultura à educação, passando pelo lazer, pela ocupação dos tempos livres e pela dinamização socioeconómica, para só falar de alguns aspectos.

10 A profunda renovação do mundo dos museus, muitos dos quais, na atualidade, são condicionados pela equação marketing-shopping-turismo e estatísticas, sendo obrigados à readequação dos seus espaços em função da indústria do entretenimento (o que não é nem consensual, nem geral), constitui também outro dos temas centrais desta colectânea.

11 A renovação museológica é, nesta colectânea, analisada sob diversas perspetivas, ora sob o ponto de vista dos recursos humanos, refletindo-se sobre os riscos de desestruturação da profissão de conservador ou sobre a emergência de novas profissões ligadas à comunicação com o público ou à gestão cultural (p. 93-104); ora sobre o conceito de não-público elaborado por Pierre Bourdieu e Alain Darbel; ora, ainda, sobre o papel dos museus na regeneração urbana, cujo exemplo bem conhecido é o do Museu Guggenheim, de Bilbau.

12 Finalmente, são, ainda, equacionados os desafios que o museu instituição, enquanto indústria da cultura, enfrenta na atualidade, seja a da forte concorrência dos novos media e da revolução do visual e do virtual, seja a das suas estratégias comunicacionais, 
sobretudo quando o frenesim expositivo conduz à negligência de funções essenciais de um museu (recolher, conservar, documentar, investigar), seja a da escassez de recursos.

Sustentado numa investigação profunda, científica e metodologicamente conduzida, este livro equaciona tópicos importantes das questões atuais do património e da museologia, de uma forma atraente e pedagógica. Constitui, por isso, uma obra, tanto para o grande público como um instrumento de trabalho fundamental para estudantes dessas áreas do conhecimento: a preocupação didática é uma constante, servida por uma linguagem acessível e clara e todos os textos são apoiados por listagens bibliográficas.

14 Este livro - poder-se-á dizer - cumpre plenamente o seu papel, conseguindo cativar para os assuntos que aborda leitores esquivos àquelas problemáticas. Cativar, como escrevia Saint Exupery através da voz do seu "Principezinho", significa criar laços, afinal, o aspecto mais importante do mundo dos museus e que está também presente nesta obra.

\section{AUTEURS}

\section{IRENE VAQUINHAS}

Faculdade de Letras da Universidade de Coimbra, Centro de História da Sociedade e da Cultura da Universidade de Coimbra, Portugal, irenemcv@fl.uc.pt 